\title{
An interview with Professor Farzad Sharifian
}

\author{
Musa Nushi $^{1^{*}}$, Zahra Abolhassani ${ }^{2}$ and Naiemeh Mojerloo ${ }^{1}$
}

\author{
* Correspondence: \\ M_nushi@sbu.ac.ir \\ 'Shahid Beheshti University, Evin, \\ Tehran 1983969411, Iran \\ Full list of author information is \\ available at the end of the article
}

\section{Springer}

\begin{abstract}
In this interview Professor Farzad Sharifian, a pioneer of Cultural Linguistics, gives a concise history of this relatively new field, which he introduces as a multidisciplinary area of research that examines the intricate relationship between language and cultural conceptualizations. Prof. Sharifian asserts this flourishing field of research can be applied in areas such as intercultural communication, cross-cultural pragmatics, language and politics, and World Englishes. He believes Cultural Linguistics has important implications for the practice of English Language Teaching (ELT) too, especially for Teaching English as an International Language (TEIL). Professor Sharifian also touches on the notion of "metacultural competence" and how new communication technology can help language learners develop that competence. He concludes by saying that the English as an International Language and World Englishes paradigms require us to revisit how we define and assess language proficiency and that intercultural communication skills should constitute the heart of the new definitions and assessment procedures.
\end{abstract}

Keywords: Cultural linguistics, Farzad Sharifian, Cultural conceptualizations, Metacultural competence, World Englishes, English as an international language

\section{Introduction}

Professor Farzad Sharifian holds the Chair in Cultural Linguistics at Monash University, Australia. He is also the Director of the Language and Society Centre within the School of Languages, Literatures, Cultures and Linguistics at Monash. With a multidisciplinary background in cognitive science, anthropology and education, Professor Sharifian has a broad range of research interests including Cultural Linguistics, pragmatics, English as an International Language, World Englishes, language and politics, and intercultural communication. He has widely published in many international journals and books and has been an invited keynote or plenary speaker at many international conferences.

Prof. Sharifian has been the recipient of multiple awards for his research, teaching, and postgraduate supervision, including the Edith Cowan University's Research Medal (2002), the Award for Excellence in Early Career Research of the Year, Faculty of Arts, Monash University (2008), Supervisor of the Year, Faculty of Arts, Monash University (2013) and the prestigious Humboldt Fellowship for Experienced Researchers, from the Alexander von Humboldt Foundation, Germany (2012). He is currently the President of the Applied Linguistics Association of Australia (ALAA). For more information about 
Professor Sharifian visit his webpage at Monash University: http://profiles.arts.monash.edu.au/farzad-sharifian/.

Professor Sharifian, it is a great pleasure to have this interview with you and we would like you to thank for accommodating us in your busy schedule.

Q: To start off, you are seen as a pioneer of Cultural Linguistics. Could you give us a bit of history behind this field? Why did you become interested in this branch of Linguistics?

Prof. Sharifian: First of all, I would like to thank you so much for inviting me to take part in this interview. In terms of the history of Cultural Linguistics, interest in exploring the relationship between language and culture is nothing new and, in fact, is among the oldest areas of linguistics. However, Cultural Linguistics as a multidisciplinary area of research that explores the relationship between language and cultural conceptualizations is a relatively new field.

To my knowledge, Professor Gary B. Palmer, from the University of Nevada, Las Vegas, was the first scholar who proposed what he called a "theory of cultural linguistics", which he did in his 1996 book, Toward a theory of cultural linguistics. Palmer's proposal called for three traditions in anthropological linguistics to be applied to cognitive linguistics, which was what he called cultural linguistics. Central to his proposal was the notion of 'imagery', which he argued was closely related to language and at the same time culturally constructed.

In a review of my 2011 book entitled Cultural Conceptualizations and Language: Theoretical Framework and Applications, Professor Alexandra Bagasheva states that "Sharifian lays solid theoretical and analytical grounds for what can be recognized as Cultural Linguistics." In that book I drew on theoretical and analytical advancements in several disciplines and paradigms, including cognitive psychology, cognitive anthropology, and distributed cognition, to offer a theoretical framework and an analytical framework for exploring language and conceptualizations. The book was of course the outcome of more than 10 years of research.

In the last few years, Cultural Linguistics seems to have gathered a lot of momentum. In 2014, John Benjamins launched a new journal with the title of the International Journal of Language and Culture, with me as its founding Editor-in-Chief. Springer has recently launched a book series on Cultural Linguistics, again with me as its Series Editor. And also next year, the First International Conference of Cultural Linguistics will be held in Italy, Prato. My writings have been translated into several languages including Russian and Polish. All of these, I think, are good signs of a flourishing field of research. I think the forces of globalization and increasing contact between people from different cultural backgrounds is promoting serious studies of language and culture (as a conceptual system), which is what Cultural Linguistics offers to explore.

And as to the question of why I became interested in this field, I must admit that it was my life experiences in a new cultural environment, I mean Australia, which made me more and more conscious of the relationship between language and what I now call 'cultural conceptualizations'. Around 18 years ago I migrated to multicultural Australia, from Iran, and since then I have had constant communicative interactions with speakers from many different language-culture backgrounds, and this has made me highly cognizant of the need for a framework to explore the relationship between language and culture. 
Unfortunately, in the past, studies of language and culture have suffered from loose definitions and delineations of the notion of 'culture', to the point that many scholars have either avoided/dismissed the term or have criticized its use. For many, 'culture' has been associated with stereotyping and essentializing speakers. For me, one of the strengths of Cultural Linguistics is that it avoids the use of the term 'culture' as analytical tool, and focuses on cultural conceptualizations instead. It also acknowledges diversity in cultural knowledge, particularly through the notion of heterogeneously distributed cultural conceptualizations.

Q: What is the relationship between language and culture from a Cultural Linguistics' perspective and why do you think the time-honored discipline of Linguistics is/was insufficient, theory-wise and methodology-wise, to account for the link?

Prof. Sharifian: From the perspective of Cultural Linguistics, many features of human languages encode cultural conceptualizations that are abstracted from the experiences of their speakers, past and present. This encoding is particularly obvious in words and expressions. Semantic and pragmatic meaning, if you can separate the two, are in many cases conceptualizations that are culturally constructed. I have provided many examples of these in my work, and of course they are abundant in the work of other Cultural Linguists too.

As to the second part of your question, I have not suggested that linguistics is insufficient to account for the link. Linguistics is a very broad field now and it has been able to establish links with many other disciplines to explore various aspects of human experience. Cultural Linguistics is just one of the fields that has a strong root in linguistics.

Q: You introduce Cultural Linguistics as a multidisciplinary field of research that examines the complex relationship between language and cultural conceptualizations $^{1}$ (Sharifian 2011). Could you please elaborate on the multidisciplinary nature of Cultural Linguistics?

Prof. Sharifian: In my search for theoretical and analytical notions and tools that would be fruitful for examining the relationship between language and cultural conceptualizations, I drew on several disciplines and sub-disciplines. First of all, I had a strong background in cognitive science and linguistics, which of course provided the corner stones of my thoughts. During the early years of my engagement in scholarly research, I mainly conducted experimental research within the framework of psycholinguistics. Later on, I drew on cognitive anthropology, anthropological linguistics, distributed cognition, complexity science, and cognitive linguistics, in order to develop the theoretical and analytical frameworks that I have offered for Cultural Linguistics.

Q: When developing the frameworks for Cultural Linguistics, were you also thinking about its theoretical or pedagogical implications for English Language Teaching (ELT), for instance, the implications that Cultural Linguistics might have for the major models of Communicative Competence (e.g., Bachman 1990; Canale 2014; Canale \& Swain, 1980)?

Prof. Sharifian: Absolutely. I was an English language teacher, by both training and practice, for more than a decade in Iran and for one and a half years in Australia. So, from the begging of my research in Australia, I was thinking about the implications of Cultural Linguistics research for ELT. In Australia, I became familiar with the concept of Teaching English as an International Language (TEIL), and I thought Cultural Linguistics could make significant contributions to this new paradigm in ELT. 
In fact, all along the way, I also tried to apply Cultural Linguistics to topics that would fall within the areas of intercultural communication, cross-cultural pragmatics, language and politics, and World Englishes. I edited a book with Professor Gary B. Palmer with the title of Applied Cultural Linguistics, which was published in 2007. I should add that data from applications of Cultural Linguistics to those areas that I just mentioned significantly contributed to the development of the frameworks I presented in my 2011 book. So, contrary to some other traditions, it was not the case that the frameworks were first developed and then applied to areas within applied linguistics later on. From the beginning Cultural Linguistics was strongly focused on its applicability to more practical concerns. Currently I am editing a book, Advances in Cultural Linguistics, with more than 30 chapters, and I can see that scholars around the world have applied Cultural Linguistics to many other very important and interesting topics. Of course I am very pleased about that, and I am looking forward to seeing Cultural Linguistics generating more and more studies in different languages and cultures in the future.

Q: Speaking on a more practical level, we know that culture is a crucial part of learning another language, some have even referred to it as the "fifth language skill" (Tomalin 2008), yet there is little consensus on how culture should be incorporated into classroom teaching. How can notions such "metacultural competence" (Sharifian 2013) drawn from Cultural Linguistics help language teachers move beyond traditional representations of culture in the classroom?

Prof. Sharifian: The notion of 'metacultural competence' acknowledges the fact that English is no longer the sole property of its so-called "native speakers", but it is widely used by speakers from many diverse cultural-linguistic backgrounds. Many people now live/work/study in countries other than their own, where they use English to communicate with other speakers who are not traditionally classed as "native speakers" either (think about Iranian students studying in Malaysia, for example). What these learners need is the competence to enable them to negotiate their cultural conceptualizations and communicate intercultural meanings. I think the notion of metacultural competence is a step towards achieving this. If we take this notion seriously, then we need to develop an understanding in learners that English is now an international language that is used by a very wide range of speakers who use English to express their own personal range of cultural conceptualizations. Often learners develop conceptualizations that might be new to them, for example through blending from their L1 and L2 conceptualizations. Cultural Linguistics acknowledges that an L2 often opens new conceptual horizons for learners.

So, in terms of what we could do to promote metacultural competence in ELT, I can think of at least two solutions. ELT curricula can promote awareness of some of the different systems of cultural conceptualizations associated with English. Many current textbooks just represent speakers from a particular socio-economic class, who speak a particular variety of English. I learned English through that system myself in Iran, and I was seriously handicapped when I came to Australia, as most Englishes spoken in Australia were a mystery to me.

Beyond textbooks, teachers can make use of the Internet, for example, to expose their learners to the diversity that characterizes the English language in today's world. In my days of ELT this was not possible, but these days, the Internet and new technology offer 
so many various opportunities for learning beyond the classroom. A very useful strategy would be to use the new technology to place learners in contact with language learners in other countries, where leaners from different cultural backgrounds have a chance to explicitly discuss the systems of cultural conceptualizations they are familiar with.

But I guess, the first step in the direction that I am outlining here is an attitudinal change. Many language teachers still view themselves as helping their learners achieve native-like fluency, teaching "standard" English, etc. What we are promoting here requires a different mindset, I think. It's a mindset that first acknowledges the sociocultural and sociolinguistic reality of the English language in the world today.

Q: As a follow-up to the previous question, we know that people of different cultural backgrounds learn in different ways. In the United States, for instance, students often prefer collaborative activities in which they learn from one another. In some other cultures, however, the teacher is always the center of class activities and the sole authority. Could you please tell us how concepts developed by Cultural Linguistics could benefit English as a Second (ESL) or English as a Foreign Language (EFL) teachers, particularly in terms of their awareness of learners' choice of learning and communication strategies in the classroom?

Prof. Sharifian: Yes, there are culturally constructed styles and strategies of learning, and I am not sure if the field of ELT has paid due attention to that aspect of language learning. In my own work on Aboriginal English speaking children learning Australian English as their second dialect, I noticed that these learners often engaged in learning activities that were culturally constructed. As an example, when asked to tell a story within the classroom, often they preferred to co-narrate the story in groups, rather than individually. In cases like that, I would encourage the teachers to appreciate and allow for culturally diverse styles/strategies of learning in their teaching. Cultural Linguistics does acknowledge that learning in general, and language learning in particular are at least partly culturally driven processes.

Q: You (Sharifian 2003), (Palmer \& Sharifian 2007) argue that interaction with members of a cultural group is key to developing an understanding of the cultural conceptualizations held and negotiated by that group. How can EFL learners develop such cultural conceptualizations in a learning context where they have little or no access to a particular cultural environment and its members?

Prof. Sharifian: That is a key question. I remember when I was teaching English in Iran, learners could only practice communication in English with their fellow Iranian learners. But I think the times have changed a bit. I think we can now explore the potential of the new technology for helping learners develop metacultural competence. Computer networks are currently being used in many contexts to engage learners in what is known as 'telecollaboration' or 'online intercultural exchange'. In general, I think the use of computer-mediated communication (CMC) can offer fruitful opportunities for learners to communicate with speakers from other cultural backgrounds. That is an opportunity that did not exist when I was an English language teacher.

Q: Turning to the issue of global spread of the English language, notions such as English as a Lingua Franca (ELF) (Jenkins 2000, 2003; Seidlhofer 2001), English as an International Language (EIL) (McKay 2002; Sharifian 2009; Smith 1983), World Englishes (WEs) (Kachru 1985, 1986, 2003; Kachru \& Nelson 1996) and English as a Global Language (Crystal 2003) have been met with mixed reactions. Some (e.g., 
Pennycook 1994; Phillipson 1992) believe that the spread of the English language is a serious threat to national languages and to multilingualism. Others (e.g., Crystal 1997; Graddol 2006; McKay 2002; McKay \& Bokhorst-Heng 2008) believe, implicitly or explicitly, that the global spread of English has helped intercultural understanding and international communication. We would like to ask your opinion in this regard.

Prof. Sharifian: I think there is a bit of truth in both arguments. I don't think one argument runs totally counter to the other one. But as to the question of English as a threat to multilingualism, in a recent article with the title of Teaching English as an International Language: A multilingual perspective, I argued that globalisation of English does not necessarily pose a threat to bi/multilingualism, but in fact can increase the pluricentricity of the language. English is now a truly multicultural language, as speakers from so many cultural backgrounds use English to express their cultural conceptualizations. On the other hand, some even argue that the spread of English urges the speakers of minority languages to passionately commit to maintaining their language, as it is their language links them to their own culture, history, and identity. But this is of course one thing, and the intention of those who promote English as a means of cultural and linguistic imperialism is another thing. This issue is of course very complex and has been discussed in many book length publications.

Q: Can we imagine a scenario where the global spread of the English language can be seen as a threat to the English language that is spoken in the Inner Circle countries (Kachru 1985, 1986, 2003), countries such as the United Kingdom, the United States, Australia and Canada where English is used as the primary language? For instance, we know that the spread of the English language has challenged the Inner Circle countries' “ownership" of the language, or as Graddol (1999) has stated, the spread of English has led to a decline in the proportion of people who speak English as their first language. Can the spread of English lead to the "death" of the "native" English language (i.e., the variety that is spoken in the Inner Circle countries)?

Prof. Sharifian: First of all, I don't see these arguments in black and white terms. I think the reality is much more complicated. What is clear is that the number of what we call World Englishes is on the rise, and so is the number of native speakers of these new varieties. I think what is happening is that what it means to be a "native speaker" is changing, and it is spreading from those who speak English as their first and only language, to those who may speak it as their second or third language. Today, as you have native speakers of British English, so you have native speakers of Malaysian or Singaporean English. The situation is now that if speakers of British English feel that they own British English, speakers of Malaysian English may equally feel that they own Malaysian English. Some people also argue that the language belongs to whoever uses it.

It seems to me that the phenomenon of one speaker clearly speaking one variety of English is significantly changing. Speakers' global mobility now means that many people learn one variety and then move to a context where speakers speak another variety, or have exposure to other varieties through TV/Cinema and the new technology. You could say the English of such speakers has features from more than just one variety. From a technical perspective, I think we could say "globalization is changing the patterns of speakers' lectal repertoire". 
Q: How necessary is it for ESL/EFL teachers to get familiar with EIL and WEs? Would you elaborate upon how a WEs perspective can contribute to language pedagogy, for example, to teacher education or curriculum design?

Prof. Sharifian: First of all, as you know many scholars have argued that EFL/ESL terminology is no longer valid, at least in many contexts. Many of the contexts which were once characterized as EFL or ESL may now be classified as EIL. But on the question of the contribution of a WEs perspective to language pedagogy, I think it is absolutely necessary that we familiarize ELT teachers with WE and encourage them to adopt a WE-based pedagogy in their teaching. The reason why is very simple: our learners are likely to end up communicating with speakers of Englishes other than American and British English, and we need to prepare them for that. It's as simple as that. Just take the case of Iran: many learners of English there will eventually travel to countries such as Malaysia, China, Turkey, UAE, either for leisure, or to study or work. Naturally our English teaching needs to prepare our learners to communicate with speakers of different varieties of English, and this can be best achieved, I think, if we adopt a WE-based approach to our teacher training.

Q: On a related note, should ESL/EFL learners be taught or exposed to WEs? If so, what variety of English? A mixture of several varieties? If ESL/EFL learners get exposed to one variety, might we not run the risk of replacing one "prominent" variety such as British or American English with another "emergent" variety such as "China English" which may turn into a "prominent" variety in the future?

Prof. Sharifian: That is a very good question. Some teachers assume that in promoting Teaching English as an International Language and a WE-based ELT we are encouraging them to teach different varieties of English. We often hear certain teachers saying 'my students don't need to speak Chinese English". That is really not what the argument is. The argument is that at some level of learning when learners have grasped some mastery of English, we need to expose them to certain amount of the variation that characterizes World Englishes. To begin with, this is to help them develop what is called 'multidialectal competence' in English, part of which is the ability to comprehend (and not to speak) various varieties of English.

Also, I think we often have the mistaken assumption that whatever variety we teach in the classroom will eventually be the variety that learners will end up speaking. I think each learner will 'develop' their own idiolect, which is likely to reflect more than just the variety(ies) that they have been taught. We often underestimate factors such as identity and ultimately cultural conceptualizations that learners draw on when they use any language.

Q: Do you not think that EIL causes a bit of conflict in language learners? On the one hand, learners try to learn English for international communication and on the other hand, they wish to maintain their cultural identity like accent, lexis, pragmatic norms. Do you see it as a conflict?

Prof. Sharifian: Well, it depends on how you define EIL, I guess. My version of EIL simply acknowledges the legitimacy of learners' Englishes, in the sense that the English language that a competent learner ultimately ends up speaking may reflect their (desired) identity, the cultural conceptualizations that they draw on, etc. I think it is impossible to separate language from the influence of those factors, be it for local communication or international/intercultural communication. 
Q: Does the EIL or WEs paradigm require us to conceptualize the notion of language proficiency in a new or different way? What would be the challenges of the new conceptualization for testing and assessment (of language proficiency)?

Prof. Sharifian: Of course it does! In recent decades we have witnessed significant geographical, demographic, and structural changes to the English language, and this requires us to revisit notions such as 'language proficiency'. I think no matter how we define language proficiency in today's world, intercultural communication skills should be at the heart of it. As you rightly point out, this will then have serious implications for how we assess proficiency too. Some scholars, including James Dean Brown, have recently written on this topic, but I think in terms of actual language testing, we have a long way to go. Whenever we raise an issue about testing, some people raise concerns such as 'ease of administration'. Often academic arguments and non-academic concerns don't match up in the area of language testing. I know major commercial language tests have been trying to include some diversity of language use in their tests, but I am not sure if that is enough to capture the kind of intercultural communication skills that I am referring to here.

Q: How do you think the new opportunities afforded by technological advancement will shape or change EIL? What would be the possible implications of this change for language educators and learners?

Prof. Sharifian: The whole paradigm of EIL partly owes its emergence to the new technology. CMC is one of the contexts in which the distinction between EFL and ESL is blurred. The new technology is a significant channel for the use of English as an International language. As I mentioned earlier, we could now embrace CMC and use it to provide learners with opportunities to engage in intercultural communication with learners in various other parts of the world. And I think that is the starting point for developing what I have called metacultural competence. The new technology can be used to raise learners' awareness of different varieties of English and different systems of cultural conceptualizations.

Q: And finally, what prompted the Farzad Sharifian PhD Scholarship? What do you hope to achieve, locally and globally, by the scholarship?

Prof. Sharifian: The scholarship is very close to my heart. In the year 2000, the award of two scholarships by the Australian government and Edith Cowan University provided me with a great opportunity to conduct research for three years which really laid the foundation for the frameworks that I referred to earlier. My humble hope is to provide a similar opportunity for others. At the same time, this is one small way for me to promote Cultural Linguistics and its potential for improving intercultural communication. The world is suffering so much from intercultural misunderstandings and conflict at the moment. I really hope that eventually this will be a very small step towards the betterment of human relations and the human condition.

Thank you so much for providing this opportunity for me to share my thoughts with the TESOL community.

\section{Method}

The interviewers conducted the interview with Professor Sharifian online, namely through E-mail. 


\section{Results and discussion}

The results of the interview are convincing arguments by Professor Sharifian that Cultural Linguistics has important implications for TESOL/ELT/TEIL.

\section{Conclusions}

The main conclusion of this interview, as suggested by Professor Sharifian is that the English as an International Language and World Englishes paradigms require EFL/ESL experts to reconceptualize the notion of language proficiency and how it should be assed. He also proposes that that intercultural communication skills should constitute the heart of the new conceptualization and assessment procedures.

\section{Endnotes}

${ }^{1}$ Cultural conceptualizations are the ways in which people across different cultural groups construe various aspects of the world and their experiences (Sharifian 2003).

\section{Competing interests}

We have read and understood the Asian-Pacific Journal of Second and Foreign Language Education policy on declaration of interests and declare that we have no financial, professional or personal competing interests that might have influenced the performance or presentation of the work described in this manuscript.

Date: 12/1/2016.

Musa Nushi, Zahra Abolhassani and Naiemeh Mojerloo.

\section{Authors' contributions}

MN reviewed Professor Sharifian's major publications and selected the themes to be included in the interview. ZA and NM developed the interview questions based on the selected themes. They were careful to write questions that focused on the applicability of Cultural Linguistics to ELT and TEIL. MN then reviewed and refined the questions with regard to their language and content. He also added and deleted some questions. MN also did all the corresponding with Professor Sharifian. ZA proofread the finished product and NM formatted the references based on the Asian-Pacific Journal of Second and Foreign Language Education style guide. All authors read and approved the final manuscript.

\section{Authors' information}

Musa Nushi holds a Ph.D. in TEFL from Allameh Tabataba'i University in Tehran and an M.A. in the same field from the University of Tehran. He has taught English to Iranian EFL learners and teachers for almost 12 years. He also spent the 2005-2006 academic year teaching Farsi in Portland State University, in Oregon, the United States. Currently, he is an assistant professor in Shahid Behehsti University. He is also cooperating with the Organization for Researching and Composing University Textbooks in the Humanities (SAMT) in the development of a new generation of English for Specific Purposes (ESP) books for Iranian universities.

Zahra Abolhassani holds a Ph.D. in linguistics from the University of Tehran. She has been teaching in different Iranian universities at graduate and postgraduate levels, with a specialization in sociolinguistics. She was also a lecturer in Charles University in Prague, the Czech Republic, from 2011 to 2013. She is currently an assistant professor in the Research and Development Center of the Organization for Researching and Composing University Textbooks in the Humanities (SAMT). Dr. Abolhassani is also head of the Language Studies of the SAMT. Naiemeh Mojerloo is an M.A. candidate in the department of English Language and Literature of Shahid Beheshti University.

\section{Acknowledgements}

We cannot thank Professor Farzad Sharifian enough for accommodating us in his busy professional schedule. He not only answered the interview questions meticulously, but aslo provided us with his books and papers generously, replied to our many emails promptly, and helped us kindly when we faced problems in the processes of preparing, conducting and submitting the interview. Thank you dear Dr. Sharifian so much.

\section{Author details}

${ }^{1}$ Shahid Beheshti University, Evin, Tehran 1983969411, Iran. ${ }^{2}$ Center for Research and Development, the Organization for Researching and Composing University Textbooks in the Humanities (SAMT), Jalal Ale Ahamd highway, west of Yadegar e Emam Bridge, Tehran, Iran.

Received: 25 January 2016 Accepted: 23 February 2016

Published online: 20 April 2016

\section{References}

Bachman, L. F. (1990). Fundamental considerations in language testing (1st ed.). Oxford: Oxford University Press. Canale, M. (2014). From communicative competence to communicative language pedagogy. In J. C. Richards \& R. W. Schmidt (Eds.), Language and communication (pp. 2-27). London: Routledge. 
Canale, M., \& Swain, M. (1980). Theoretical bases of communicative approaches to second language teaching and testing. Applied Linguistics, 1(1), 1-47.

Crystal, D. (1997). English as a global language (1st ed.). Cambridge: Cambridge University Press.

Crystal, D. (2003). English as a global language (2nd ed.). Cambridge: Cambridge University Press.

Graddol, D. (1999). The decline of the native speaker. AllA Review, 13, 57-68.

Graddol, D. (2006). English next. London: British Council.

Jenkins, J. (2000). The phonology of English as an international language. Oxford: Oxford University Press.

Jenkins, J. (2003). World Englishes. London: Routledge.

Kachru, B. B. (1985). Standards, codification and sociolinguistic realism: the English language in the outer circle. In R. Quirk \& H. G. Widdowson (Eds.), English in the world: teaching and learning the language and literatures (pp. 11-30). Cambridge: Cambridge University Press.

Kachru, B. B. (1986). The alchemy of English. Oxford: Pergamon Press.

Kachru, B. B. (2003). On nativizing mantra: identity construction in Anglophone Englishes. In R. Ahrens, D. Parker, K. Stierstorfer, \& K. Tam (Eds.), Anglophone Cultures in Southeast Asia (pp. 50-72). Heidelberg: Universitatsverlag.

Kachru, B. B., \& Nelson, C. L. (1996). World Englishes. In S. L. McKay \& N. H. Hornberger (Eds.), Sociolinguistics and language teaching (pp. 71-102). Cambridge: Cambridge University Press.

McKay, S. L. (2002). Teaching English as an international language: rethinking goals and approaches. Oxford: Oxford University Press.

McKay, S. L., \& Bokhorst-Heng, W. D. (2008). International English in its sociolinguistic contexts: towards a socially sensitive Ell pedagogy (1st ed.). New York: Routledge.

Palmer, G. B., \& Sharifian, F. (2007). Applied cultural linguistics: an emerging paradigm. In F. Sharifian \& G. B. Palmer (Eds.), Applied cultural linguistics: implications for second language learning and intercultural communication (pp. 1-14). Amsterdam/Philadelphia: John Benjamins.

Pennycook, A. (1994). The cultural politics of English as an international language. London: Longman.

Phillipson, R. (1992). Linguistic imperialism (1st ed.). Oxford: Oxford University Press.

Seidlhofer, B. (2001). Closing a conceptual gap: the case for a description of English as a Lingua Franca. International Journal of Applied Linguistics, 11, 133-158.

Sharifian, F. (2003). On cultural conceptualisations. Journal of Cognition and Culture, 3, 187-207.

Sharifian, F. (2009). English as an international language: perspectives and pedagogical issues. Bristol/Buffalo: Multilingual Matters.

Sharifian, F. (2011). Cultural conceptualisations and language: theoretical framework and applications. John Benjamins: Amsterdam/Philadelphia.

Sharifian, F. (2013). Cultural linguistics and intercultural communication. In F. Sharifian \& M. Jamarani (Eds.), Language and intercultural communication in the New Era (pp. 60-79). Oxford: Routledge/Taylor and Francis.

Smith, L. E. (1983). Readings in English as an international language (1st ed.). Oxford/New York: Pergamon Press.

Tomalin B. Culture - the fifth language skill. [http://www.teachingenglish.org.uk/article/culture-fifth-language-skill]. Accessed Oct 2015

\section{Submit your manuscript to a SpringerOpen ${ }^{\circ}$} journal and benefit from:

- Convenient online submission

- Rigorous peer review

- Immediate publication on acceptance

- Open access: articles freely available online

- High visibility within the field

- Retaining the copyright to your article 